\title{
Reliability and Accuracy of Static Parameters Obtained From Ink and Pressure Platform Footprints
}

\author{
Juan Carlos Zuil-Escobar, PT, MSc, PhD, ${ }^{a}$ Carmen Belén Martínez-Cepa, PhD, ${ }^{a}$ \\ Jose Antonio Martín-Urrialde, PhD, ${ }^{a}$ and Antonia Gómez-Conesa, PhD ${ }^{b}$
}

\begin{abstract}
Objective: The purpose of this study was to evaluate the accuracy and the intrarater reliability of arch angle (AA), Staheli Index (SI), and Chippaux-Smirak Index (CSI) obtained from ink and pressure platform footprints.

Methods: We obtained AA, SI, and CSI measurements from ink pedigraph footprints and pressure platform footprints in 40 healthy participants (aged $25.65 \pm 5.187$ years). Intrarater reliability was calculated for all parameters obtained using the 2 methods. Standard error of measurement and minimal detectable change were also calculated. A repeated-measure analysis of variance was used to identify differences between ink and pressure platform footprints. Intraclass correlation coefficient and Bland and Altman plots were used to assess similar parameters obtained using different methods.

Results: Intrarater reliability was $>0.9$ for all parameters and was slightly higher for the ink footprints. No statistical difference was reported in repeated-measure analysis of variance for any of the parameters. Intraclass correlation coefficient values from AA, SI, and CSI that were obtained using ink footprints and pressure platform footprints were excellent, ranging from 0.797 to 0.829 . However, pressure platform overestimated AA and underestimated SI and CSI. Conclusions: Our study revealed that AA, SI, and CSI were similar regardless of whether the ink or pressure platform method was used. In addition, the parameters indicated high intrarater reliability and were reproducible. (J Manipulative Physiol Ther 2016;39:510-517)
\end{abstract}

Key Indexing Terms: Flatfoot, Foot Deformities; Foot Diseases; Reliability, Data Accuracy

\section{INTRODUCTION}

The foot has important impact absorption and ground reaction force transmission functions in both gait and bipedal standing position. ${ }^{1}$ Medial longitudinal arch (MLA) is one of the most important foot structures related to these actions ${ }^{2}$ because it participates in the absorption of ground forces. ${ }^{3}$

The height of the MLA has been considered to be a relevant factor in injuries in the lower extremity. ${ }^{4-6}$ A high MLA can increase the risk of injuries on the lateral side of the foot, whereas a lower MLA can increase the risk of injuries on the medial side. ${ }^{5}$ Changes in MLA height are related to certain injuries, such as tibial stress syndrome, ${ }^{7,8}$ patellofemoral syndrome, ${ }^{9-11}$ noncontact cruciate anterior ligament

\footnotetext{
${ }^{a}$ Nursing and Physiotherapy Department, CEU San Pablo University, Madrid, Spain.

b Physiotherapy Department, University of Murcia, Murcia, Spain. Corresponding author: Juan Carlos Zuil-Escobar, PT, MSc, $\mathrm{PhD}$, Avda De Montepríncipe s/n, 28668, Boadilla del Monte, 28668, Spain. (e-mail: jczuil@ceu.es).

Paper submitted January 15, 2015; in revised form July 13, 2016; accepted July 13, 2016.

0161-4754

Copyright (C) 2016 by National University of Health Sciences. http://dx.doi.org/10.1016/j.jmpt.2016.07.005
}

injury, ${ }^{12,13}$ and low back pain. ${ }^{14}$ In addition, the height of the MLA is related to several alignments in the lower limb. A higher MLA is associated with supination, and a lower MLA is associated with subtalar pronation. ${ }^{15}$ Changes in the MLA are associated with tibial internal rotation, ${ }^{16}$ anterior knee laxity, ${ }^{17}$ greater genu recurvatum, ${ }^{18}$ and increased pelvis anteversion. ${ }^{19}$

Many different techniques can be used to evaluate the height of the MLA, including radiographs ${ }^{20}$ visual observation, ${ }^{21}$ rearfoot angle measurements, ${ }^{22}$ navicular tuberosity measurements, ${ }^{23}$ and footprint parameters. ${ }^{24}$ Many parameters can be obtained from footprints, including arch angle (AA), arch index (AI), ${ }^{24}$ Chippaux-Smirak Index (CSI) ${ }^{25}$ long plantar arch, ${ }^{26}$ and Staheli Index (SI), ${ }^{27}$ using ink and digital systems. Ink footprint is a valid method that is used in clinical practice to study foot structure, explore $\mathrm{MLA}^{24}$ and diagnose pathologic conditions. ${ }^{2,20}$ In addition, ink footprint is a simple, inexpensive, and noninvasive method that can be recorded for future comparisons ${ }^{28,29}$ and has correlation with radiologic measures. ${ }^{30}$ However, ink footprints have some limitations, such as the inaccuracy of the measurements and the difficulties involved in their interpretation. ${ }^{2}$ Nowadays, these limitations have been overcome by the use of digital systems, which provide both qualitative and quantitative data. ${ }^{2}$ These systems, including 


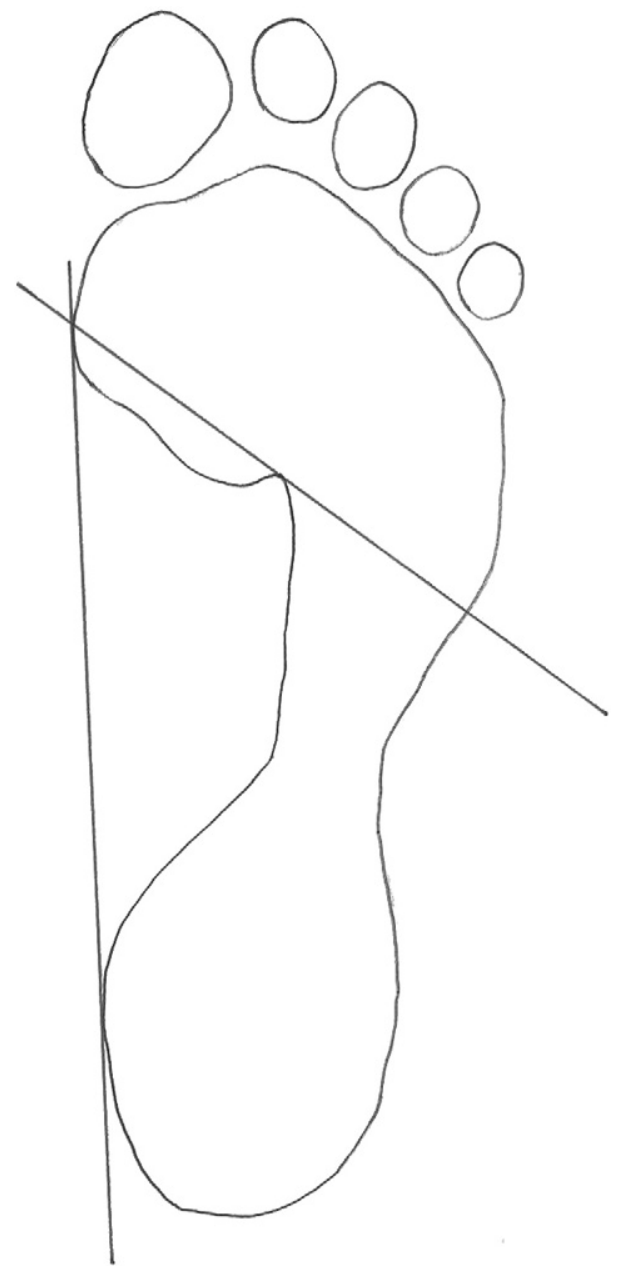

Fig I. Arch angle is the angle between the medial line of the footprint and the line connecting the most medial aspect of the metatarsus and the most lateral point of the medial foot.

pressure platforms, are widely used in investigation and clinical practice. ${ }^{2,27,31,32}$ Pressure platforms are an easier, though more expensive, means of obtaining footprints.

The aims of this study included the evaluation of the accuracy and significant differences among 3 parameters (AA, SI, and CSI) obtained using ink footprints and pressure platform footprints and the evaluation of the intrarater reliability, standard error of measurement (SEM), and minimal detectable change (MDC) of these measurements for both methods.

\section{Methods}

Forty healthy participants ( 25 women and 15 men) took part in the study after completing a form to ensure that they met the inclusion criteria. The principles outlined in the Declaration of Helsinki of 1975 were observed, and this study was approved by the research ethics committee of the CEU San Pablo University. Each participant was informed about the aims and

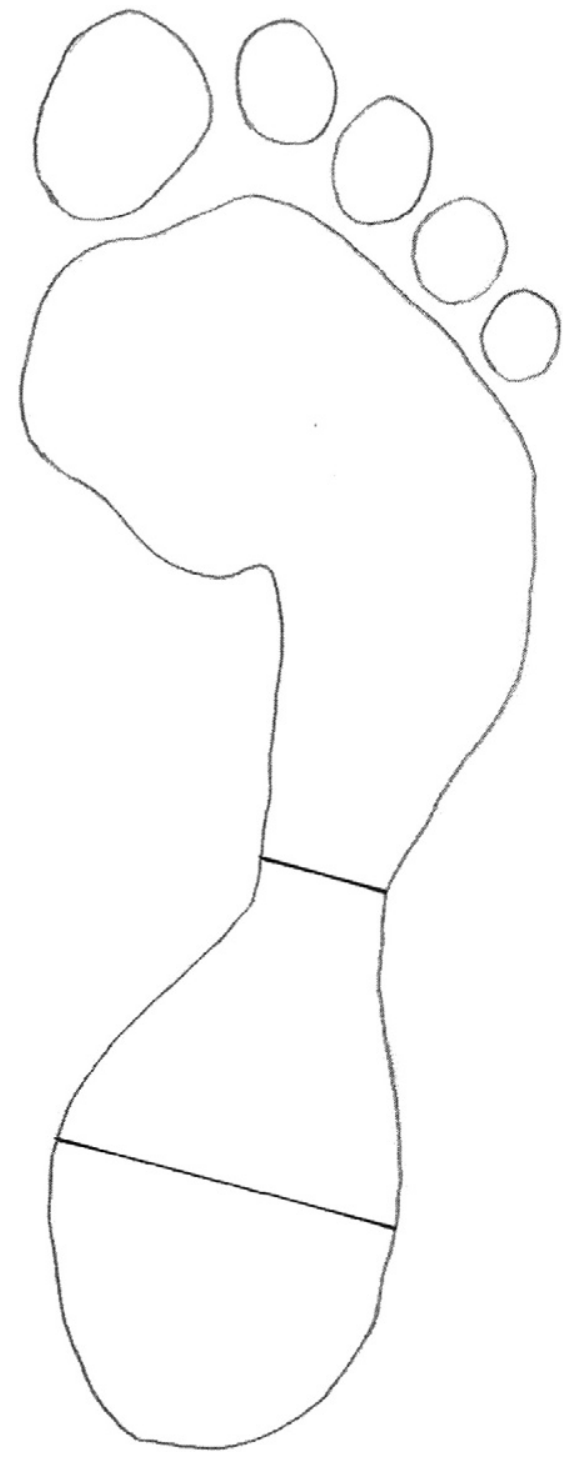

Fig 2. Staheli Index is obtained by dividing the minimal distance of the midfoot by the widest section of the rearfoot region.

procedure and completed a consent form before being included in the study. Participants experiencing acute injuries in lower limbs, having undergone surgery, or presenting with deformities in the feet were excluded. Demographic variables including age, sex, height, weight, and body mass index were collected from those who were eligible.

Right feet were studied in each participant. ${ }^{2}$ Three parameters were used to measure arch height: AA, SI, and CSI. AA is the angle between the medial line of the footprint and the line connecting the most medial aspect of the metatarsus and the most lateral point of the medial foot (Fig 1). ${ }^{33}$ To calculate SI and CSI, 3 lines were drawn: 1 at the maximal distance of the rearfoot, 1 at the maximal distance of the forefoot, and 1 at the minimal distance of the midfoot. ${ }^{6}$ The SI is the ratio of the minimal distance of the midfoot to the widest section of the rearfoot region (Fig 2). ${ }^{25}$ The CSI is obtained by 


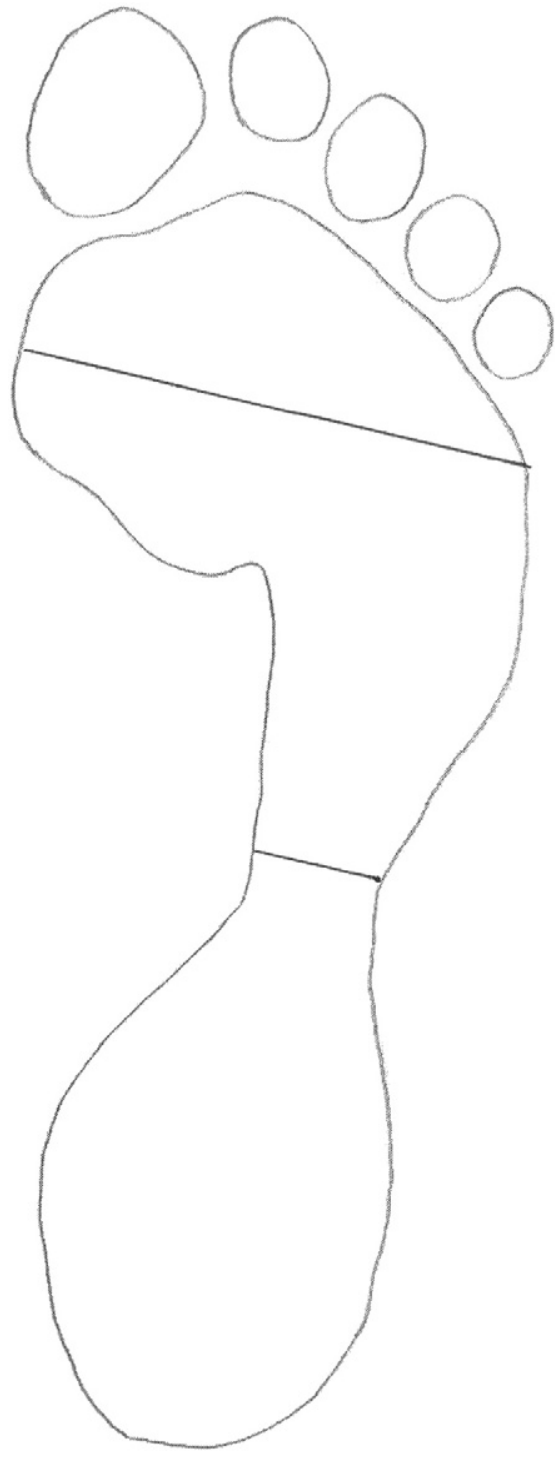

Fig 3. Chippaux-Smirak Index is obtained by dividing the minimal distance of the midfoot by the maximal distance of the forefoot.

dividing the minimal distance of the midfoot by the maximal distance of the forefoot (Fig 3). ${ }^{25}$

These variables were collected using footprints obtained from 2 instruments: a pressure platform and an ink pedigraph. The pressure platform (Footchecker; Loran Engineering, Bologna, Italy) was connected to a personal computer by means of complementary software (Footchecker 3 ) and placed on a firm surface. To collect digital footprints, participants were asked to place their bare foot on the platform and maintain a stable posture, with their arms relaxed against their body, and to look at a reference point located $1.8 \mathrm{~m}$ from the floor $(3 \mathrm{~m}$ in front of them). Data were captured when participants were stable, using a 15 -second trial. Ink footprints were collected using an ink pedigraph. Participants remained in the same position for the pressure platform footprints and ink footprints collection. Three trials were measured for each method and were repeated if participants lost balance. Methods to collect footprints were randomized.

Statistical analysis was conducted using IBM SPSS Statistics 20 (IBM Corp, Armonk, NY) and executed at 95\% confidence level. Normal distribution of quantitative variables was assessed using the Kolmogorov-Smirnov test. Descriptive analysis was conducted using means and standard deviations (SD). First, the intrarater reliability of ink footprints and pressure platform footprints were evaluated using the intraclass correlation coefficient (ICC) and 95\% confidence intervals (CIs). Standard error of measurement and MDC were also calculated. To evaluate differences between ink and pressure platform footprints, the averages of the 3 trials collected by the 2 instruments were used. A repeated-measure analysis of variance (ANOVA) was used to identify differences. Intraclass correlation coefficient and Bland and Altman plots were performed to assess similar parameters obtained with the different methods. Reliability was interpreted as follows: poor $(0-0.39)$, modest $(0.4-0.74)$, or excellent $(\geq 0.75){ }^{34}$

\section{RESULTS}

The sample consisted of 25 women and 15 men with a mean age of 25.65 years ( \pm 5.187 years), a mean height of $167 \mathrm{~cm}$ ( \pm $9.727 \mathrm{~cm})$, a mean body weight of $65.185 \mathrm{~kg}( \pm 10.747 \mathrm{~kg})$, and a mean body mass index of $23.204 \mathrm{~kg} / \mathrm{m}^{2}\left( \pm 2.442 \mathrm{~kg} / \mathrm{m}^{2}\right)$. All ink footprint and pressure platform footprint variables studied had a normal distribution in the Kolmogorov-Smirnov test $(P>$ .05 ). Intrarater reliability for both methods was excellent (ICC > $0.9)$ and was slightly higher for ink footprint variables. Mean, $\mathrm{SD}$, SEM, MDC, and ICC of ink footprint and pressure platform footprint measurements are presented in Table 1.

No statistical difference was reported in repeated-measure ANOVA for AA $(F=1.884)$, SI $(F=2.668)$, and CSI $(F=$ 3.760) obtained using the different methods. However, in the pressure platform method, SI and CSI were underestimated and AA overestimated.

Intraclass correlation coefficients and $95 \% \mathrm{CI}$ values obtained from AA, SI, and CSI using ink footprints and pressure platform footprints are shown in Table 2. In all variables, ICCs were excellent, ranging from 0.797 to 0.829 . Figures 4, 5, and 6 show Bland and Altman plots. Staheli Index and CSI obtained using pressure platform footprints were lower than those obtained using the ink pedigraph; however, pressure platform AA was higher than that of the ink pedigraph.

\section{DISCUSSION \\ Reliability}

In this study, the evaluated parameters (AA, SI, and CSI) obtained from ink footprints and pressure platform footprints revealed excellent intrarater reliability. Intraclass correlation coefficient was $>0.9$ in all variables and had a 
Table I. Mean, SD, SEM, MDC, and ICC (95\% Confidence Interval) Obtained by Ink Footprints and Pressure Platform Footprints

\begin{tabular}{|c|c|c|c|c|c|c|c|c|c|c|}
\hline & \multicolumn{5}{|c|}{ Ink Footprints } & \multicolumn{5}{|c|}{ Pressure Platform Footprints } \\
\hline & Mean & SD & SEM & MDC & ICC & Mean & SD & SEM & MDC & ICC \\
\hline Arch angle & 45.275 & 6.185 & 0.978 & 2.711 & $0.975(0.952-0.986)$ & 46.100 & 7.186 & 1.223 & 3.390 & $0.974(0.935-0.990)$ \\
\hline Staheli Index & 0.458 & 0.071 & 0.010 & 2.789 & $0.980(0,963-0,989)$ & 44.445 & 7.977 & 1.358 & 3.764 & $0.971(0.946-0.984)$ \\
\hline Chippaux-Smirak Index & 29.255 & 5.581 & 0.728 & 2.010 & $0.983(0.968-0.991)$ & 28.153 & 6.667 & 1.174 & 3.254 & $0.969(0.924-0.988)$ \\
\hline
\end{tabular}

ICC, intraclass correlation coefficient; $M D C$, minimal detectable change; $S D$, standard deviation; $S E M$, standard error of measurement.

$P$ values for ICC $<.01$.

Table 2. ICC and Confidence Level of Arch Angle, Staheli Index, and Chippaux-Smirak Index

\begin{tabular}{lll}
\hline & ICC & $95 \%$ CI \\
\hline Arch angle & 0.829 & $0.700-0.906$ \\
Staheli Index & 0.806 & $0.662-0.892$ \\
Chippaux-Smirak Index & 0.797 & $0,648-0,887$ \\
\hline
\end{tabular}

$C I$, confidence interval; $I C C$, intraclass correlation coefficient.

$P$ values for ICC $<.01$.

slightly higher reliability in ink footprints. In our sample, AA, SI, and CSI obtained using both methods were reproducible. Reliability literature has reported similar results. Intrarater reliability of footprint parameters has been studied by several authors. Although AI is the most commonly evaluated parameter, ${ }^{6,35,36}$ AA, SI, and CSI have also been evaluated. Queen et $\mathrm{al}^{6}$ studied the reliability of various footprint parameters, which included SI, CSI, and AA, using the mirrored foot photo box in 30 healthy participants in static conditions. All parameters revealed good interrater and between-day reliability. Staheli Index was the most interrater reliable (ICC $=0.963)$, followed by CSI $(\mathrm{ICC}=0.961)$ and AA $(\mathrm{ICC}=0.957)$. In between-day reliability, although ICC for AA was 0.638, SI and CSI were $>0.9$. Papuga and Burke ${ }^{37}$ studied intrarater and interrater reliability of AA, SI, and CSI in 32 healthy participants, using a digital foot scanner in static conditions with 30 -second trials. Interrater ICC was $>0.880$ for CSI and SI and ranged between 0.605 and 0.895 for AA. Intrarater ICC was $>0.9$, except in AA of 1 rater (0.817). Fascione et $\mathrm{al}^{36}$ evaluated the SI and CSI intrarater reliability of 10 adults in dynamic conditions using an ink mat. They obtained an ICC of 0.99 for both.

Intrarater reliability has been evaluated in children too. Dowling et $\mathrm{al}^{29}$ reported intrarater reliability of $\mathrm{ICC}=0.999$ for AA and CSI obtained from ink footprints. In 2014, Fascione et $\mathrm{al}^{38}$ studied the between-day reliability of the static and dynamic AA and AI in 21 children. The reliability of the AI was excellent, both static (ICC $=0.89-0.92)$ and dynamic ( ICC $=0.86-0.92)$. However, the AA had poor to excellent static reliability $(\mathrm{ICC}=0.27-0.84)$ and moderate to excellent dynamic reliability ( $\mathrm{ICC}=0.66-0.88$ ). Nikolaidou and Boudolos ${ }^{35}$ evaluated - also in children - the intrarater reliability of AA and CSI obtained from ink, using Bland and Altman limits of agreement and finding a high degree of

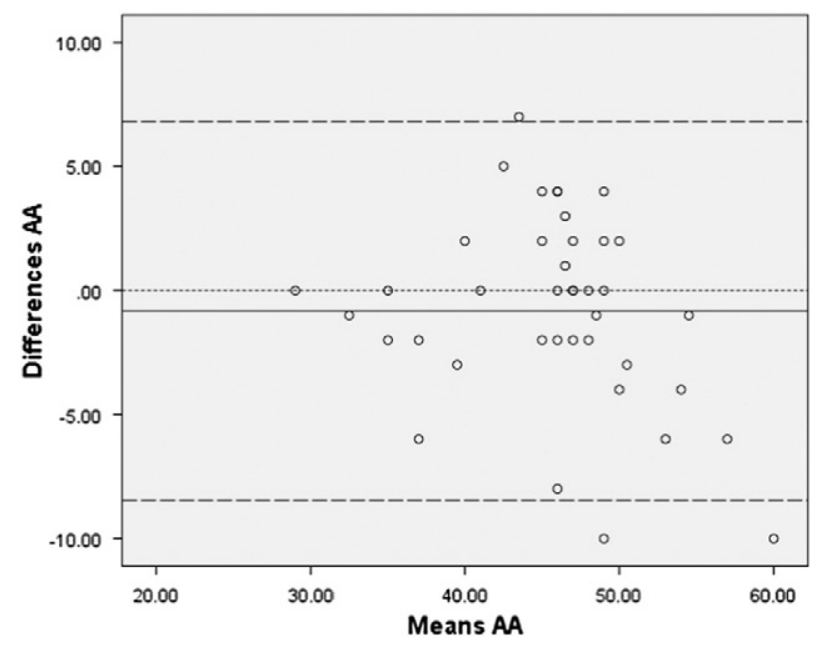

Fig 4. Bland and Altman plots for arch angle (AA). Mean bias (-0.825), as unbroken lines, indicates that the pressure platform overestimated arch angle. The limits of agreement (-8.447 and 6.797) are indicated by dashed lines.

repeatability. In our study, SEM and MDC values were low for both methods and slightly lower in ink footprints. In 2004, Fascione et $\mathrm{al}^{38}$ reported SEM values similar for dynamic AA $(\mathrm{SEM}=0.6-1.5)$ and higher for static AA (SEM = 1.2-6.2). Akins et $\mathrm{al}^{39}$ presented high values for AA $(\mathrm{SEM}=12.58)$. We have not found other studies that evaluated the SEM or MDC for SI and CSI. According to our results and the literature, footprint ink and pressure platform parameters have high reliability and are reproducible.

\section{Accuracy}

Regarding the accuracy of ink footprint and pressure platform footprint parameters evaluated, repeated-measure ANOVA reported no statistical differences in the parameters studied. In addition, ICCs obtained in a comparison of the 2 methods in all variables were excellent, exceeding 0.75. Bland and Altman plots reported that pressure platform overestimated AA and underestimated SI and CSI.

Several authors have suggested that measurements taken using a pressure platform underestimated midfoot area, both in static $^{26,40}$ and dynamic conditions. ${ }^{36,38}$ In 2005, Urry and Wearing ${ }^{26}$ reported that the greatest discrepancies were observed in high MLA feet in static evaluation. However, in the present research, we did not evaluate specifically planus or cavus feet. 


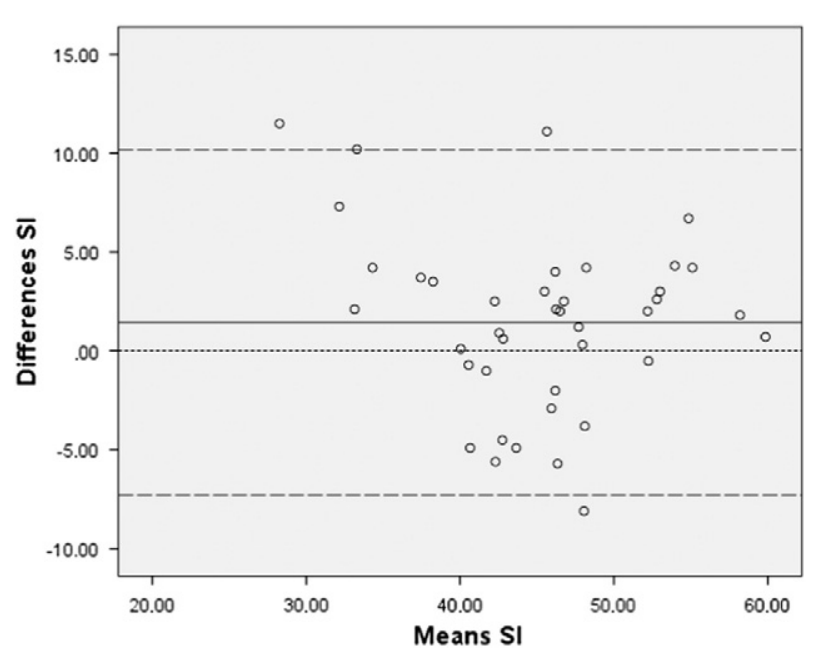

Fig 5. Bland and Altman plots for Staheli Index (SI). Mean bias (1.443) indicates that the pressure platform underestimated the SI. The limits of agreement (-7.293 and 10.178) are indicated by dashed lines.

Parameters based on foot contact area were not used in this study because the area obtained from pressure platform footprints differed from that obtained from ink footprints. In 2001, Urry and Wearing ${ }^{40}$ reported that foot contact area and AI were smaller in electronic platforms than in ink footprints. They suggested that the pressure platform particularly underestimated the middle part of the foot. However, the platform's software did not allow automatic calculation of either the foot contact area or the AI; the authors calculated contact area by multiplying the number of activated sensors by the area of a single sensor. They concluded that platforms with greater spatial resolution and sensors with a low pressure threshold were necessary.

In 2005, Urry and Wearing ${ }^{26}$ carried out a similar study comparing foot contact area and AI using a capacitive transducer pressure platform and dividing the foot contact area into 5 regions. They reported that the accuracy of the contact area was site dependent. Total foot contact area was not statistically different between ink footprints and electronic footprints. However, the pressure platform overestimated heel area (relatively small) and underestimated midfoot and lesser toes (by $10.2 \%$ and $17.7 \%$, respectively). In addition, AI derived from a pressure platform was smaller than that obtained from ink because the midfoot area was underestimated. However, high correlation ( $r=0.938$ ) was obtained. The authors suggested that capacitive sensors result in smaller errors in estimating close heel and forefoot contact area but not midfoot area. In 2010, Xiong et $\mathrm{al}^{2}$ studied the correlation between different parameters, including AI obtained from ink paper and F-scan. They obtained a high correlation $(r=0.841)$. Ink AI had moderate to high correlation with other parameters, such as normalized navicular height or arch height index.

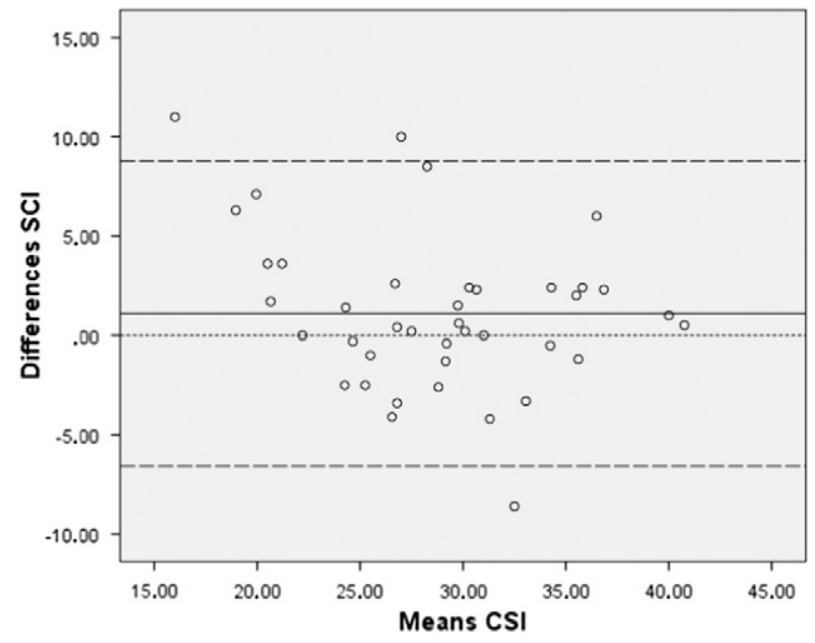

Fig 6. Bland and Altman plots for Chippaux-Smirak Index (CSI). Mean bias (1.443) indicates that the pressure platform underestimated the CSI. The limits of agreement (-6.578 and 8.784) are indicated by dashed lines.

It is presumed that the reliability of the footprint obtained with an electronic platform is influenced by spatial resolution and the pressure threshold of the sensors. ${ }^{28}$ The underestimation of the midfoot area indicates that the pressure threshold can be influenced significantly. ${ }^{26}$ For this reason we preferred not to use foot contact area parameters and chose angle and index instead. In addition, we used a trial length of 15 seconds because we had observed that this trial length allowed a high level of reliability for pressure platform parameters in a previous study. ${ }^{41}$

Studies evaluating correlations or accuracy of AA, SI, and CSI acquired by 2 methods in static conditions were not found; however, some references relating to the evaluation of footprint parameters were found. In previous studies, Urry and Wearing ${ }^{26,40}$ also studied long arch angle. This is the angle formed by the intersection of the tangents to the lateral borders of the foot contact area. ${ }^{23}$ In 2001, Urry and Wearing ${ }^{40}$ reported no statistical differences between ink long arch angle and electronic long arch angle. However, they reported low correlation $(r=0.432)$. In 2005, Urry and Wearing $^{26}$ reported high correlation $(r=0.924)$, but statistical differences between the long arch angle were obtained using 2 different methods. We prefer to evaluate AA because this is a more commonly used angle in clinical practice and investigation for which correlations with radiologic parameters have been reported. ${ }^{42}$

In this study, we have assessed the accuracy of several ink and pressure platform footprint parameters in static conditions. Fascione et $\mathrm{al}^{36}$ evaluated the relationship between certain footprint parameters in dynamic conditions, including SI and CSI, using ink mat, paper pedography, electronic pedograph, and a 30-participant 
sample. Intraclass correlation coefficients ranged from 0.29 to 0.79 . Staheli Index had 0.43 and CSI, 0.29. In addition, they obtained statistical differences in repeated-measure ANOVA. These data differed from our results. Fascione et $\mathrm{al}^{36}$ evaluated dynamic footprints, whereas our study was performed in static conditions. In addition, several electronic footprints did not reveal complete midfoot contact, reducing the sample size by 10 participants (33.3\% of the total sample), and they were unable to calculate SI and CSI. In our study, in static conditions and with 15 -second trial length, all pressure platform footprints had contact in the midfoot area.

This research was the first to assess the accuracy of AA, SI, and CSI collected by ink footprints and digital footprints. The absence of any statistical differences and the high ICCs suggest that, in our sample, the 2 systems may be interchangeable. Nevertheless, a degree of caution is required because the pressure platform underestimated SI and CSI and overestimated AA.

The evaluation of the MLA is necessary in clinical practice. There is no general consensus on an ideal method for the evaluation of the MLA and for foot type classification. ${ }^{20}$ Footprint parameters are commonly used. 2,27,31,32 Changes in the orientation of the components of the foot would be reflected in footprint. ${ }^{20}$ Footprints can be collected using ink and digital systems. ${ }^{2,20}$ According to our results and the literature, footprint parameters are reproducible and simple methods to evaluate the height of the MLA. Our research reported that the parameters evaluated (AA, SI, and CSI) using ink and digital footprints are similar, being not statistically different. Digital systems, including pressure platforms, are expensive. Ink footprints are inexpensive and accessible for clinical practitioners.

\section{Limitations}

Our study has certain limitations. We evaluated AA, CSI, and SI but not foot contact area, AI, or other foot contact area parameters. Although foot contact area and AI have been evaluated by other authors, ${ }^{2,26,40}$ it is necessary to update the accuracy of ink mat footprints and pressure platform footprints, considering that the spatial resolution and sensor threshold of pressure platforms are better. Our study presented a heterogeneous group with regard to foot type, including normal, low, and high MLA. It is necessary to compare these parameters by means of homogeneous foot type, specifically high-arched foot. ${ }^{26}$ In addition, the sample size included in our study (adults) limited the generalization of the results to other populations (children and older people).

\section{CONCLUSIONS}

This study reported that AA, SI, and CSI obtained from ink footprints and pressure platform footprints had high intrarater reliability and were reproducible. In addition, AA, SI, and CSI obtained using the 2 methods were similar. These parameters were not statistically different between methods and had high ICC. The pressure platform overestimated AA and underestimated SI and CSI. The results suggest, in our sample, that these methods may be used interchangeably.

\section{FundING SOURCES AND CONFLICTS OF INTEREST}

No funding sources or conflicts of interest were reported for this study.

\section{CONTRIBUTORSHIP INFORMATION}

Concept development (provided idea for the research): J.C.Z.-E., C.B.M.-C., J.A.M.-U., A.G.-C.

Design (planned the methods to generate the results): J.C.Z.-E., C.B.M.-C., J.A.M.-U., A.G.-C.

Supervision (provided oversight, responsible for organization and implementation, writing of the manuscript): J.C.Z.-E., C.B.M.-C., J.A.M.-U., A.G.-C.

Data collection/processing (responsible for experiments, patient management, organization, or reporting data): J.C.Z.-E.

Analysis/interpretation (responsible for statistical analysis, evaluation, and presentation of the results): J.C.Z.-E., C.B.M.-C., J.A.M.-U., A.G.-C.

Literature search (performed the literature search): J.C.Z.-E., C.B.M.-C.

Writing (responsible for writing a substantive part of the manuscript): J.C.Z.-E., C.B.M.-C., J.A.M.-U., A.G.-C.

Critical review (revised manuscript for intellectual content, this does not relate to spelling and grammar checking): J.C.Z.-E., C.B.M.-C., J.A.M.-U., A.G.-C.

\section{Practical Applications}

- Both footprint parameters showed excellent intrarater reliability.

- No statistical differences were reported for any parameters obtained using 2 methods.

- Footprint parameters obtained by 2 methods were similar.

- Pressure platforms overestimated AA and underestimated SI and CSI. 


\section{REFERENCES}

1. Fiolkowski P, Brunt D, Bishop M, Woo R, Horodyski MB. Intrinsic pedal musculature support of the medial longitudinal arch: an electromyography study. J Foot Ankle Surg. 2003; 42(6):327-333.

2. Xiong S, Goonetilleke RS, Witana CP, Weerasinghe TW, Au EY. Foot arch characterization: a review, a new metric, and a comparison. J Am Podiatr Med Assoc. 2010;100(1):14-24.

3. Nielsen RG, Rathleff MS, Simonsen OH, Langberg H. Determination of normal values for navicular drop during walking: a new model correcting for foot length and gender. $J$ Foot Ankle Res. 2009;2:12.

4. Williams DS, McClay IS. Measurements used to characterize the foot and the medial longitudinal arch: reliability and validity. Phys Ther. 2000;80(9):864-871.

5. Williams 3rd DS, McClay IS, Hamill J. Arch structure and injury patterns in runners. Clin Biomech (Bristol, Avon). 2001;16(4):341-347.

6. Queen RB, Mall NA, Hardaker WM, Nunley 2nd JA. Describing the medial longitudinal arch using footprint indices and a clinical grading system. Foot Ankle Int. 2007;28(4):456-462.

7. Moen MH, Bongers T, Bakker EW, et al. Risk factors and prognostic indicators for medial tibial stress syndrome. Med Sci. 2012;22(1)34-39.

8. Newman P, Witchalls J, Waddington G, Adams R. Risk factors associated with medial tibial stress syndrome in runners: a systematic review and meta-analysis. Sports Med. 2013;4:229-241.

9. Barton CJ, Bonanno D, Levinger P, Menz HB. Foot and ankle characteristics in patellofemoral pain syndrome: a case control and reliability Study. J Orthop Sports Phys Ther. 2010;40(5): 286-296.

10. Molgaard C, Rathleff MS, Simonsen O. Patellofemoral pain syndrome and its association with hip, ankle and foot function in 16- to 18-year-old high school students: a single-blind casecontrol study. J Am Podiatr Med Assoc. 2011;101(3):215-222.

11. Boling MC, Padua DA, Marshal SE, Guskiewicz K, Pyne S, Beutler A. A prospective investigation of biomechanical risk factors for patellofemoral pain syndrome: the Joint Undertaking to Monitor and Prevent ACL Injury (JUMP-ACL) cohort. Sports Med. 2009;37(11):2108-2116.

12. Hertel J, Dorfman JH, Braham RA. Lower extremity malalignnments and anterior cruciate ligament injury history. J Sports Sci Med. 2004;3(4):220-225.

13. Loudon JK, Jenkins W, Loudon KL. The relationship between static posture and ACL injury in female athletes. J Orthop Sports Phys Ther. 1996;24(2):91-97.

14. Brantingham JW, Lee Gilbert J, Shaik J, Globe G. Sagittal plane blockage of the foot, ankle and hallux and foot alignment-prevalence and association with low back pain. $J$ Chirop Med. 2006;5(4):123-127.

15. Donatelli R. Normal biomechanics of the foot and ankle. $J$ Orthop Sports Phys Ther. 1985;7(3):91-95.

16. Tiberio D. The effect of excessive subtalar joint pronation on patellofemoral mechanics: a theoretical model. J Orthop Sports Phys Ther. 1987;9:160-165.

17. Shultz SJ, Nguyen AD, Levine BJ. The relationship between lower extremity alignment characteristics and anterior knee joint laxity. Sports Health. 2009;1(1):54-60.

18. Nguyen AD, Shultz SJ. Identifying relationships among lower extremity alignment characteristics. J Athl Train. 2009;44(5): 511-558.

19. Pinto RZ, Souza TR, Trede RG, Kirkwood RN, Figueiredo EM, Fonseca ST. Bilateral and unilateral increase in calcaneal eversion affect pelvic alignment in standing position. Man Ther. 2008;13(6):513-519.

20. Razeghi M, Batt ME. Foot type classification: a critical review of current methods. Gait Posture. 2002;15(3):282-291.

21. Dahle LK, Mueller MJ, Delitto A, Diamond JE. Visual assessment of foot type and relationship of foot type to lower extremity injury. J Orthop Sports Phys Ther. 1991; 14(2):70-74.

22. Tsai LC, Yu B, Mercer VS, Groos MT. Comparison of different structural foot types for measures of standing postural control. J Orthop Sports Phys Ther. 2006;36(12): 952-953.

23. Brody DM. Techniques in the evaluation and treatment of the injured runner. Am. 1982;13(3):541-558.

24. Cavanagh PR, Rodgers MM. The arch index: a useful measure from footprints. J Biomech. 1987;20(5):547-551.

25. Forriol F, Pascual J. Footprint analysis between three and seventeen years of age. Foot Ankle. 1990;11(2):101-104.

26. Urry SR, Wearing SC. Arch indexes from ink footprints and pressure platforms are different. Foot. 2005;15(2):68-73.

27. Chen CH, Huang MH, Chen TW, Weng MC, Lee CL, Wang GJ. The correlation between selected measurements from footprint and radiograph of flatfoot. Arch Phys Med Rehabil. 2006;87(2):235-240.

28. Urry SR, Wearing SC. The accuracy of footprint contact area measurements: relevance to the design and performance of pressure platforms. Foot. 2001;11(3):151-157.

29. Dowling AM, Steele JR, Baur LA. Can static plantar pressures of prepubertal children be predicted by inked footprints? $J \mathrm{Am}$ Podiatr Med Assoc. 2004;94(5):429-433.

30. Menz HB, Munteanu SE. Validity of 3 clinical techniques for measurement of static foot posture in older people. J Orthop Sports Phys Ther. 2005;35(8):479-486.

31. McPoil TG, Cornwall MW. Use of plantar contact area to predict medial longitudinal arch height during walking. $\mathrm{J} \mathrm{Am}$ Podiatr Med Assoc. 2006;96(6):489-494.

32. Wearing SC, Hills AP, Byrne NM, Henniq EM, McDonald M. The arch index: a measure of flat or fat feet? Foot Ankle Int. 2004;25(8):575-581.

33. Chuckpaiwong B, Nunley JA, Mall NA, Queen RM. The effect of foot type on in-shoe plantar pressure during walking and running. Gait Posture. 2008;28(3):405-411.

34. Fleiss J. The Design and Analysis of Clinical Experiments. New York, NY: Wiley; 1999.

35. Nikolaidou ME, Boudolos KD. A footprint-based approach for the rational classification of foot types in young schoolchildren. Foot. 2006;16(2):82-90.

36. Fascione JM, Crews RT, Wrobel JS. Dynamic footprint measurement collection technique and intrarater reliability: ink mat, paper pedography and electronic pedography. $J$ Am Podiatr Med Assoc. 2012;102(2):130-138.

37. Papuga MO, Burke R. The reliability of the associate platinum digital foot scanner in measuring previously developed footprint characteristics: a technical note. J Manip Physiol Ther. 2011;34:114-118.

38. Fascione JM, Crews RT, Wrobel JS. Association of footprint measurements with plantar kinetics: a linear regression model. J Am Podiatr Med Assoc. 2014;104(2):125-133.

39. Akins JS, Keenan KA, Sell TC, Abt JP, Lephart SM. Test-retest reliability and descriptive statistics of geometric measurements based on plantar pressure measurements in a healthy population during gait. Gait Posture. 2012;35(1):167-169.

40. Urry SR, Wearing SC. A comparison of footprint indexes calculated from ink and electronic footprints. $\mathrm{J} \mathrm{Am} \mathrm{Podiatr}$ Med Assoc. 2001;91(4):203-209. 
41. Zuil JC, Martínez CB. Estudio de fiabilidad y descriptivo de las variables de presión plantar mediante plataforma de presión. XI Jornadas Nacionales y I Congreso Internacional de Fisioterapia de la Actividad Física y el Deporte; 2009. Madrid, Spain.
42. Villaroya MA, Esquivel JM, Tomás C, Moreno LA, Buenafé A, Bueno G. Assessment of the medial longitudinal arch in children and adolescents with obesity: footprints and radiographic study. Pediatr. 2009;168(5):559-567. 